\title{
Modified Quad surgery significantly improves the median nerve conduction and functional outcomes in obstetric brachial plexus nerve injury
}

\author{
Rahul K Nath", Nirupuma Kumar and Chandra Somasundaram
}

\begin{abstract}
Background: Nerve conduction studies or somatosensory evoked potentials (SSEPs) have become an important tool in the investigation of peripheral nerve lesions, and is sensitive in detecting brachial plexus nerve injury, and other nerve injuries.

To investigate whether the modified Quad surgical procedure improves nerve conductivity and functional outcomes in obstetric brachial plexus nerve injury (OBPI) patients.

Methods: All nerves were tested with direct functional electrical stimulation. A Prass probe was used to stimulate the nerves, and recording the response, the compound motor action potential (CMAP) in the muscle. SSEP monitoring was performed pre- and post modified Quad surgery, stimulating the median and ulnar nerves at the wrist, the radial nerve over the dorsum of the hand, recording the peripheral, cervical and cortical responses. All patients have had the modified Quad surgery $(n=19)$. The modified Quad surgery is a muscle release and transfer surgery with nerve decompressions. All patients were assessed preoperatively and postoperatively by evaluating video recordings of standardized movements, the modified Mallet scale to index active shoulder movements.
\end{abstract}

Results: The cervical responses were significantly lower in amplitude in the affected arm than the un-affected arm. The median nerve conduction was significantly improved from 8.04 to $9.26(P<0.022)$ post-operatively. The shoulder abduction was also significantly improved (pre-op $30^{\circ} \pm 23.3$ to $143^{\circ} \pm 33.7, p<0.0001$ ), with a mean follow-up of 43 months after the modified Quad surgery in these patients.

Conclusion: Median nerve conduction, and shoulder abduction were significantly improved in OBPI children, who have undergone the modified Quad procedure with neuroplasty, internal microneurolysis and tetanic stimulation of the median nerve.

Keywords: Obstetric brachial plexus nerve injury, Electromyography, Nerve conduction study, Somatosensory evoked potentials, Shoulder abduction, Modified Quad surgery

\section{Background}

Indications and timing, as well as type of surgical repair are important questions in the management of obstetric brachial plexus injury (OBPI). Delay to time of surgery often results in progressive worsening of deformity in the shoulder joint as contractures progress quickly over time in a rapidly growing infant [1]. Diagnostic tools used to identify which lesions are permanent in OBPI include CT, MRI, myelogram, and electromyography (EMG) as well as nerve conduction velocity (NCV)

\footnotetext{
*Correspondence: drnath@drnathmedical.com

Texas Nerve and Paralysis Institute, 6400 Fannin st, Houston, TX 77030, USA
}

studies [2-5]. Distinguishing preganglionic (avulsion) from postganglionic (rupture) lesions is critical, and can be difficult at initial presentation based on clinical examination alone in these infants $[6,7]$.

Nerve conduction studies or somatosensory evoked potentials (SSEPs) have become an important tool in the investigation of peripheral nerve lesions [2], and are sensitive in detecting brachial plexus nerve injury [3-8], and other nerve injuries [9]. The median nerve (MN)-SSEPs, notably the subcortical tracings have been demonstrated to be more useful for the detection of some neurological disorders in children than posterior tibial nerve (PTN)- 
Table 1 SSEPs (CERV) before and after modified Quad surgery in OBPI patients

\begin{tabular}{|c|c|c|c|c|c|}
\hline & & Ulnar-Lat Mean \pm SEM & Ulnar-Amp Mean \pm SEM & Median-Lat Mean \pm SEM & Median-Amp Mean \pm SEM \\
\hline Pre- mod Quad & Affected & $8.04 \pm 3.84$ & $2.51 \pm 1.98$ & $8.04 \pm 3.84$ & $1.91 \pm 1.49$ \\
\hline Post- mod Quad & Affected & $8.6 \pm 3.16$ & $2.44 \pm 1.63$ & $9.26 \pm 2.98$ & $2.32 \pm 1.57$ \\
\hline$N=19$ & $P=$ & 0.50 & 0.54 & 0.022 & 0.12 \\
\hline
\end{tabular}

Median nerve conduction improved significantly after MQ surgery in these patients.

SSEPs [10]. Furthermore, a significantly lower nerve conduction velocity was found in the median nerve of the injured arm of anterior interosseous nerve syndrome patients, compared to the normal arm [11].

The modified Quad procedure was performed on appropriate patients at our institute [12]. Nerve conduction testing was done just before the modified Quad surgery in these patients, and these values were compared statistically with SSEPs monitored in the same patients later in time prior to indicated bony surgery, the triangle tilt. We found there was a significant improvement in median nerve $(\mathrm{MN})$ conduction, and shoulder abduction after the modified Quad surgery in this patient population.

\section{Methods}

A retrospective chart review was conducted based on surgical cases performed at the Texas Nerve and Paralysis Institute. Inclusion criteria included infants, who showed lack of antigravity biceps functions pre-operatively, and had undergone the modified Quad surgery between 2004 and 2010. Nineteen OBPI patients, aged between 4 and 8 months (average $5 \pm 0.1$ ) were found who fit these criteria with a mean follow-up time of 43 months. This was a retrospective study of patient charts, which exempted it from the need for IRB approval in the United States. Patients were treated ethically in compliance with the Helsinki declaration. Documented informed consent was obtained for all patients.

The nerve involvement was $\mathrm{C} 5,6(\mathrm{~N}=1), \mathrm{C} 5,6,7$ $(\mathrm{N}=4)$ and $\mathrm{C} 5,6,7,8(\mathrm{~N}=5)$, and with $\mathrm{T} 1$ involvement $(\mathrm{N}=9)$.

SSEP monitoring was performed pre- and postmodified Quad surgery, stimulating the median and ulnar nerves at the wrist, the radial nerve over the dorsum of the hand, and recording the peripheral, cervical and cortical responses. All patients have had the modified Quad surgery $(n=19)$. All surgical procedures were performed by the lead author. The modified Quad [12] is a modification of the combination of muscles released and their insert positions to improve upon a previously described operation [13]. In the modified Quad procedure, the latissimus dorsi, teres major, subscapularis, and pectoralis muscle contractures are released [12]. Additionally, the axillary nerve is neurolysed. Empirically it was thought that the median nerve may be compressed by the pectoralis major muscle contracture as the two structures meet in the area of the anterior axillary fold.

\section{Mallet grading}

All patients were assessed preoperatively and postoperatively by evaluating video recordings of standardized movements using the modified Mallet scale to index active shoulder movements [14].

\section{Statistical analysis}

Paired Student's t-tests were conducted using Microsoft Excel 2003 with the Analyze-It plug-in (Redmond, WA; and Leeds, UK) to determine if differences between preoperative and postoperative shoulder abduction, and SSEPS for each function were statistically significant. The $\mathrm{p}$ values were two-tailed and considered significant if less than or equal to 0.05 .

\section{Results}

The cervical responses were significantly lower in amplitude in the affected arm than the un-affected arm. The median nerve conduction was significantly improved from 8.04 to $9.26(\mathrm{P}<0.022)$ post-operatively (Table 1$)$. We were also able to find significant functional improvement in these patients, who have undergone the modified Quad procedure. The postoperative abduction was significantly improved from $30^{\circ} \pm 23.3$ to $143^{\circ} \pm 33.7$ $(\mathrm{p}<0.0001)$ in these OBPI patients (Table 2 and Figure 1).

\section{Discussion}

Vredeveld et al., 2000 [5], and Colon et al., 2003 [4] reported the existence of an extensive innervation by the somatosensory system in infants with obstetric upper brachial palsy. C5 stimulation shows abduction of the limb and some external rotation, while C6 stimulation shows elbow flexion against gravity with some supination [6].

Unlike nerve grafting, neuroplasty with microneurolysis and tetanic stimulation has an immediate effect on muscle

Table 2 Abduction before and after modified Quad surgery in OBPI patients

\begin{tabular}{llll}
\hline Function & Pre-op & Post-op & Significance \\
& Mean \pm SEM & Mean \pm SEM & $\mathbf{p}<\mathbf{0 . 0 5}$ \\
\hline Abduction $\left(^{\circ}\right)$ & $30^{\circ} \pm 23.3$ & $143^{\circ} \pm 33.7$ & $p<0.0001$ \\
& & & $(n=19)$ \\
\hline
\end{tabular}



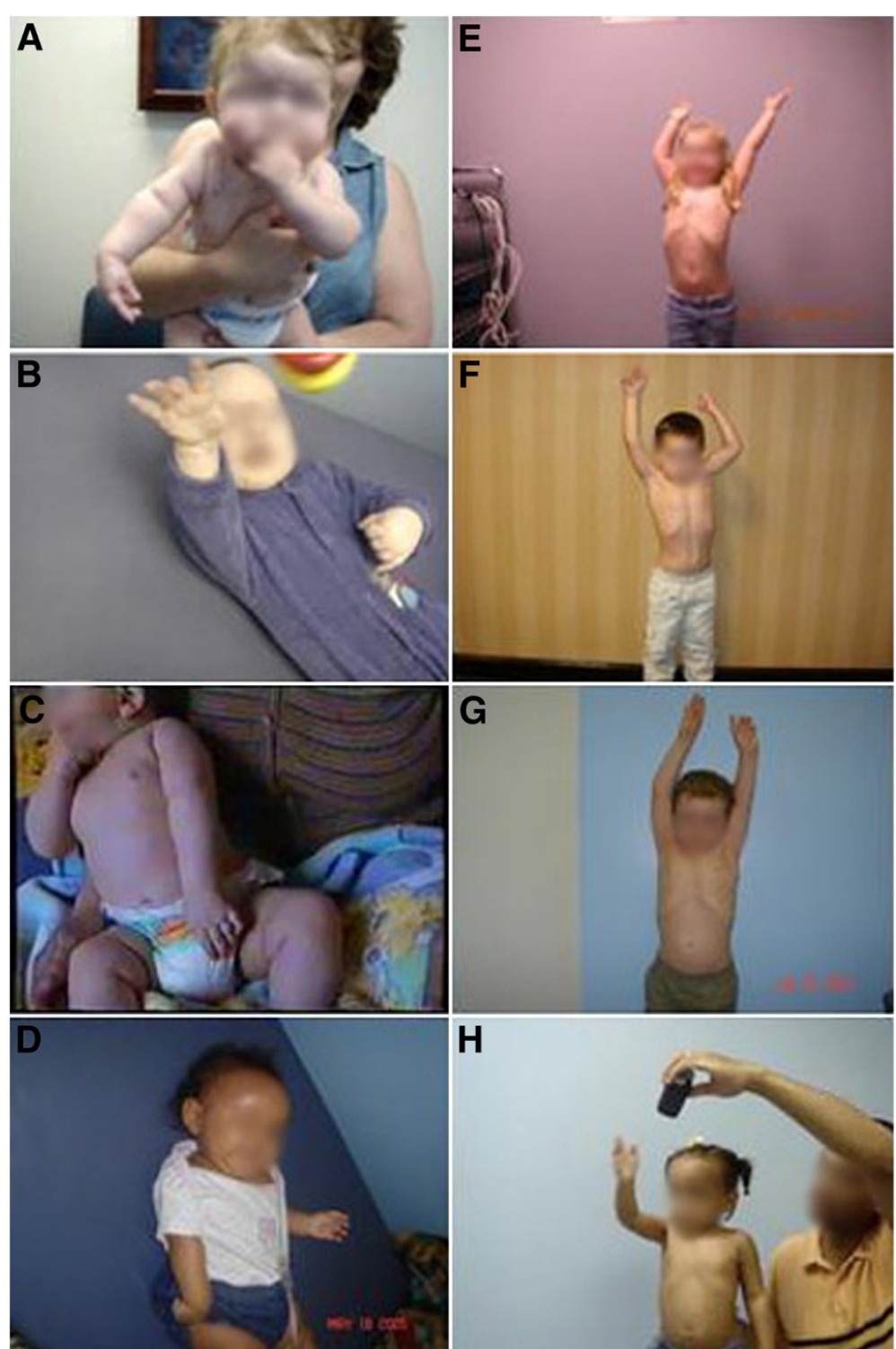

Figure 1 Comparisons of pre- and post-operative shoulder abduction in OBPI patients. A) Preoperative photograph of a 6 month old girl (A), 7 month old boys (B), (C) and (D) demonstrating limitation of shoulder movement; same patients 2.3 years (range 1.5 to 3 years) after modified Quad surgery with almost normal shoulder abduction $(\mathbf{E}, \mathbf{F}, \mathbf{G}$ and $\mathbf{H}$ ).

recovery [15]. Thus, such procedures on the axillary nerve effectively improves shoulder function since they may help to slow the acquisition of the deformity, and contractures due to progressive muscle imbalance that occur with growth. Combined with modified Quad surgery axillary neuroplasty can have a significant impact on the underlying pathophysiology of the overall shoulder joint dysfunction caused by OBPI. This was the basis for testing the distal branches of the brachial plexus specifically the median nerve, as significant improvements in hand function such as finger and wrist flexion were routinely noted immediately following modified Quad surgery.
The significant improvement noted in median nerve conduction when compared to the ulnar nerve, probably occurs because the median nerve gets decompressed during the modified Quad surgery. The median nerve decompression probably occurs due to the pectoralis major muscle contracture release during this surgery.

Performed alone neurolysis does not address the pathophysiology of OBPI injuries and does not provide relief from contractures and improve the overall stability of the shoulder joint [16-19]. By combining our approach of neurolysis with stimulation, and contracture release, we were able to achieve significant long-term 
functional improvements in these patients, in their shoulder function as well as hand function through improved median nerve function.

\section{Conclusion}

Median nerve conduction, and shoulder abduction were significantly improved in the current series of OBPI patients, who have undergone the modified Quad procedure.

\section{Competing interests}

The authors declare that they have no competing interests.

\section{Authors' contributions}

RKN conceived the study, performed the surgeries, participated in the design of the study, help to write and revised the manuscript. NK gathered and analyzed the data, and helped to draft the manuscript. CS participated in the design of the study, gathered and analyzed the data, drafted and revised the manuscript. All authors have read and approved the final manuscript.

Received: 2 January 2013 Accepted: 6 May 2013

Published: 28 May 2013

\section{References}

1. Adler JB, Patterson RL Jr: Erb's palsy. Long-term results of treatment in eighty-eight cases. J Bone Joint Surg (Am) 1967, 49:1052-1064.

2. Synek VM: Role of somatosensory evoked potentials in the diagnosis of peripheral nerve lesions: recent advances. J Clin Neurophysio/ 1987, 4:55-73.

3. Malessy MJ, Pondaag W, Yang LJ, Hofstede-Buitenhuis SM, le Cessie S, van Dijk JG: Severe obstetric brachial plexus palsies can be identified at one month of age. PLoS One 2011, 6:e26193.

4. Colon AJ, Vredeveld JW, Blaauw G, Slooff AC, Richards R: Extensive somatosensory innervation in infants with obstetric brachial palsy. Clin Anat 2003, 16:25-29.

5. Vredeveld JW, Blaauw G, Slooff BA, Richards R, Rozeman SC: The findings in paediatric obstetric brachial palsy differ from those in older patients: a suggested explanation. Dev Med Child Neurol 2000, 42:158-161.

6. Malessy MJ, Pondaag W, van Dijk JG: Electromyography, nerve action potential, and compound motor action potentials in obstetric brachial plexus lesions: validation in the absence of a "gold standard". Neurosurgery 2009, 65:A153-A159.

7. Vanderhave KL, Bovid K, Alpert H, Chang KW, Quint DJ, Leonard JA Jr, Yang $\sqcup:$ Utility of electrodiagnostic testing and computed tomography myelography in the preoperative evaluation of neonatal brachial plexus palsy. J Neurosurg Pediatr 2012, 9:283-289.

8. Li F, Gorji R, Allott G, Modes K, Lunn R, Yang ZJ: The usefulness of intraoperative Neurophysiological monitoring in cervical spine surgery: a retrospective analysis of 200 consecutive patients. J Neurosurg Anesthesiol 2012, 24:185-90.

9. Jahangiri FR, Holmberg A, Vega-Bermudez F, Arlet V: Preventing positionrelated brachial plexus injury with intraoperative somatosensory evoked potentials and transcranial electrical motor evoked potentials during anterior cervical spine surgery. Am J Electroneurodiagnostic Technol 2011, 51:198-205

10. Li L, Muller-Forell W, Oberman B, Boor R: Subcortical somatosensory evoked potentials after median nerve and posterior tibial nerve stimulation in high cervical cord compression of achondroplasia. Brain Dev 2008, 30:499-503.

11. Meya U, Hacke W: Anterior interosseous nerve syndrome following supracondylar lesions of the median nerve: clinical findings and electrophysiological investigations. J Neurol 1983, 229:91-96.

12. Nath RK, Paizi M: Improvement in abduction of the shoulder after reconstructive soft-tissue procedures in obstetric brachial plexus palsy. J Bone Joint Surg Br 2007, 89:620-626.

13. Narakas AO: Muscle transpositions in the shoulder and upper arm for sequelae of brachial plexus palsy. Clin Neurol Neurosurg 1993, 95(Suppl):S89-S91.

14. Birch R: Late sequelae at the shoulder in obstetrical palsy in children. In Surgical techniques in orthopaedics and traumatology: Shoulder. Volume 3.
Edited by Randelli M, Karlsson J. Paris: Elsevier; 2001. 55-200-E-210: Surgical Techniques in Orthopaedics and Traumatology.

15. Nath RK, Melcher S: Rapid recovery of serratus anterior muscle function after microneurolysis of long thoracic nerve injury. I Brachial Plex Peripher Nerve Inj 2007, 2:4.

16. Capek L, Clarke HM, Curtis CG: Neuroma-in-continuity resection: early outcome in obstetrical brachial plexus palsy. Plast Reconstr Surg 1998, 102:1555-1562. discussion 1563-1554.

17. Duclos L, Gilbert A: Obstetrical palsy: early treatment and secondary procedures. Ann Acad Med Singapore 1995, 24:841-845.

18. Gilbert A: Long-term evaluation of brachial plexus surgery in obstetrical palsy. Hand Clin 1995, 11:583-594. discussion 594-585.

19. Gilbert A, Abbott IR: Long-term evaluation of brachial plexus surgery in obstetrical palsy. Hand Clin 1995, 11:583-595.

doi:10.1186/1750-1164-7-5

Cite this article as: Nath et al:: Modified Quad surgery significantly improves the median nerve conduction and functional outcomes in obstetric brachial plexus nerve injury. Annals of Surgical Innovation and Research 2013 7:5.

\section{Submit your next manuscript to BioMed Central and take full advantage of:}

- Convenient online submission

- Thorough peer review

- No space constraints or color figure charges

- Immediate publication on acceptance

- Inclusion in PubMed, CAS, Scopus and Google Scholar

- Research which is freely available for redistribution 